\title{
A REESTRUTURAÇÃO DA INDÚSTRIA TÊXTIL NO ESTADO DE SÃO PAULO
}

Sandra Lencioni*

\section{OFIODAMEADA}

Este texto procura contribuir para o conhecimento da relação Espaço-Sociedade através da discussão da reestruturação da indústria têxtil no Estado de São Paulo. A nosso ver, a reestruturação da indústria têxtil está associada ao aprofundamento do processo de centralização do capital acompanhado da expansão do em torno metropolitano. Reestruturação industrial e urbana que testemunham a existência de interações entre os processos sociais e espaciais, em que a dialética desses processos reforça e consolida a metrópole de São Paulo.

Em primeiro lugar gostaríamos de destacar que a indústria têxtil é fortemente concentrada no Brasil. Das indústrias, cerca de $10,5 \%$ são indústrias de grande porte e responsáveis por $83,5 \%$ da receita do setor. ${ }^{1}$ As médias e pequenas empresas participam muito pouco na receita, indicando uma estrutura industrial fortemente concentrada. Estrutura industrial concentrada, porque mesmo havendo uma profusão de indústrias, grande parte do faturamento resulta de um pequeno número delas.

Em segundo, observar que embora o capital nacional domine o setor têxtil, vale mencionar a importância crescente que o capital estrangeiro vem tendo no desenvolvimento desta indústria. Os principais grupos econômicos estrangeiros que atuam no setor dedicam-se, sobretudo, à produção de fibras artificiais e sintéticas e suas indústrias figuram entre as maiores do país. ${ }^{2}$ Da listagem das 20 maiores empresas têxteis do país, publicada pela revista Exame de 1990, 6 são multinacionais, voltadas, sobretudo, para o mercado internacional. De controle inglês, temos a Linhas Correntes; holandês, a Cobafi e Polyenka e, japonês, Toyobo e Kanebo. Além do mais, estas empresas respondiam por $19,9 \%$ da receita operacional bruta das maiores empresas têxteis do país. $^{3}$

Estas indústrias e as grandes indústrias nacionais dominam o setor têxtil. Este pequeno número, quando se analisa a propriedade do capital, se torna um número menor ainda. Ou seja, quando se desloca do enfoque que toma as unidades industriais como referência de análise para se deter na análise da propriedade dos capitais. É possível verificar que muitas unidades fabris fazem parte de uma mesma empresa que controla o ciclo de valorização dos capitais das indústrias sobre seu comando. Em outros termos, um mesmo poder econômico, uma mesma direção de gestão mobiliza e controla os ciclos de valorização do capital segmentado em diversas unidades de produção. A empresa, como unidade que centraliza capitais, é nosso referencial de análise, bem como a recente reestruturação espacial das indústrias têxteis no Estado de São Paulo.

\section{TECENDO CONSIDERAÇÕES SOBREA REESTRUTURAÇÃODAINDÚSTRIA TÊXTILNO ESTADO DE SÃOPAULO}

A década de oitenta foi de recessão econômica. É sabido que nos momentos em que os lucros se vêem mais ameaçados, cria-se um vasto campo para as estratégias de

(*) Professora Assistente Doutora do Departamento de Geografia da Faculdade de Filosofia, Letras e Ciências Humanas da Universidade de São Paulo.

(1) Os dados se referem ao biênio 1980/1981, segundo MIC/CDI/SIND: 1982.

(2) Diferentemente da indústria de tecelagem, em que as grandes empresas são basicamente nacionais, com exceção das que produzem os tecidos "indigo blue," na produção de fibras artificias predominam as empresas multinacionais. Cabe ressalvar que dentre as empresas indicadas não estão incorporadas duas grandes empresas que embora atuem no setor têxtil, dada a importância de suas outras atividades, não são classificadas como do setor têxtil. São a Rhodia (Rhône-Poulenc), francesa e Bunge Y Born, argentina. $\mathrm{O}$ grupo francês participa dos setores químico e farmacêutico e, o segundo, dos setores alimentos e igualmente, químico. Tanto uma quanto outra, estão presentes dentre os 40 maiores grupos econômicos estrangeiros que participam na produção nacional, levandose em consideração todas as atividades econômicas. Gazeta Mercantil: Balanço Anual/1990.

(3) Exame: agosto/1990; 269. 
centralização. ${ }^{4}$ Muito embora seja difícil quantificar o número de empresas que passaram pelo processo de centralização, vale afirmar que foram nos momentos de mais aguda recessão econômica que houve uma tendência à associações, fusões e absorções, em que aparentemente parece sobreviver apenas aquelas empresas que puderam se modernizar, aumentar a produtividade e competir no mercado internacional. ${ }^{5} \mathrm{Em}$ outros termos, os momentos de ajuste estrutural, como no início dos anos 80 , criaram um vasto campo para as estratégias de centralização.

Dentre as maiores empresas têxteis, citamos alguns exemplos de centralização, divulgados pela imprensa a título de ilustração da força deste processo de controle do capital. A Alpargatas cujo controle acionário é do Banco Brasileiro de Descontos - um dos maiores bancos do país - e também da Brasmotor e Participações Molho Velho - grandes grupos econômicos -, em 1982 comprou $92,3 \%$ do capital votante da Têxtil Gabriel Calfat do Nordeste S/A, localizada em Aracaju. ${ }^{6}$ Em 1981 adquiriu a Alpargatas da Argentina. ${ }^{7}$ Neste mesmo ano, comprou a Malharia Azoni S. A. de São Carlos. ${ }^{8}$ Com mais de 21 empresas em 1983, empregava 28.000 trabalhadores. $^{9}$ Em 1994 se fundiu com a Santista compondo um conglomerado que fatura cerca de US\$ 400 milhões anuais. ${ }^{10}$

O grupo Vicunha atua nos setores de fiação e tecelagem, confecções e comércio de fios e tecidos. Tem sua origem na associação da Têxtil Campo Belo (Rabinovich) e Têxtil Elizabeth (Steinbruch). Posteriormente adquiriram o Lanificio Varam, a Indústria Têxtil São Sebastião, a Indústria Têxtil Stral, a Fiação São Manuel, a Indústria Têxtil Anápolis, e um antigo lanifício inglês. Associou-se, ao Sul, ao grupo Renner do Rio Grande do Sul e no Nordeste do país, criou a Lanotops que mais tarde se desdobrou na Têxtil R.V. e Artefatos Têxtil R.V., e a FINOBRASA - Fiação Nordeste do Brasil. Também arrendou a Tinturaria Brasileira de Tecidos e a Textilia S.A, pertencente anteriormente a um grupo francês. ${ }^{11}$

A expansão deste grupo incluiu a compra de uma indústria de origem italiana, com sede na Suiça, mais precisamente, a Fibra S/A - Fiação Brasileira de Rayon..$^{12}$ Recentemente a FIBRA se fundiu com a "Du Pont para fabricação de náilon. ${ }^{13}$ Possui mais de 10 empresas e várias unidades fabris, tais como a Jurici S/A Comercial e Importadora, Agro Fisap, Rodoviária Veldog S/A, Lee S/A Indústria de Confecções, Indústria Cearense de Confecções - Lee Nordeste -, sendo as duas últimas em associação com a Renner, de Porto Alegre e a Lee Americana. ${ }^{14}$
Outro caso de interesse é o da Cianê - Companhia Nacional de Estamparia - uma das maiores empresas do país, do grupo Severino Pereira da Silva, que em 1983 adquiriu a Divisão Têxtil da Matarazzo, chegando, assim, a 10 unidades fabris no setor têxtil. Em 1990 a Cianê ocupava o 5o

(4) "A crise econômica brasileira, as altas taxas de juros e o grande endividamento das empresas internamente e no Exterior estão aumentando o número de empresários que procuram vender suas propriedades ou associar-se a grupos mais fortes, segundo revelou ontem o diretor da Price Waterhouse Auditores Independentes. A situação de endividamento das sociedades brasileiras hoje compromete os seus resultados. As empresas, em busca de capital de giro, tomaram financiamentos internos e externos, 'a juros bastante superiores à inflação,' disse. Assim, segundo o diretor da 'Price,' muitos empresários se defrontaram com o dilema de vender seus negócios ou associar-se a outros grupos" O Estado de São Paulo, 8 de agosto de 1983.

(5) A quantificação do número de associações, absorções e fusões das empresas é muito difícil se ser feita porque não há estatísticas disponíveis a respeito. No entanto, através de levantamentos em sete jornais do pais, compreendendo praticamente a segunda metade da década de oitenta e o ano de 1990, foi possível detectar alguns casos de associações, absorções e fusões ocorridos na indústria têxtil, incluindo-se aí a indústria de confecções. Em 1985 ocorreram 2 casos; em 1986, 8; em 1987, 6; em 1988, 17 e em 1990, 7. Fonte: Levantamento Price Waterhouse, 1991, mimeo.

(6) Gazeta Mercantil, 09/07/1981.

(7) Folha de São Paulo, 08/06/1982.

(8) Gazeta Mercantil, 03/10/1981.

(9) Diário Comércio e Indústria, 18/05/1983.

(10) O Estado de São Paulo, 27/06/1994.

(11) Textiles Panamericanos: março/1982; 26.

(12) Nesta ocasião a imprensa declarou que a compra desta multinacional fez com que a Vicunha entrasse para "o clube fechado da produção de fibras químicas, junto com a Rhodia e a Celanese..." Estado de São Paulo: 26/07/1982.

De fato, esta compra representou, segundo o empresário Benjamim Steinbruch, diretor superintendente do grupo, que com a nacionalização da Fibra se "incrementará a produção de poliester, náilon e rayon-viscose, em que aquela empresa mantinha participação significativa no mercado... Mas o mais importante é que nós compramos tecnologia. Teremos assessoramento tecnológico da Sniafibra, italiana, por dez anos, o que significa, na prática, equipamentos para o desenvolvimento de produtos novos com custo mais barato." (O Estado de São Paulo, 26/07/1982).

(13) O Estado de São Paulo, 27/06/1994.

(14) Gazeta Mercantil, 15/07/1982. 
lugar entre as maiores empresas têxteis do país. Cabe mencionar que este grupo atua também nos setores de cimento, transporte, mineração e agro-pecuária. ${ }^{15}$

Além destes casos, haveriam outros dignos de nota. Conforme o quadro acima, mesmo uma quantificação incipiente baseada em notícias divulgadas pela imprensa desde 1985, as empresas têxteis, incluindo o ramo de confecções, estiveram envolvidas em associações, absorções e fusões, como outros setores industriais durante estes anos de recessão econômica.

É importante esclarecer que as associações, absorções e fusões implicam na formação e expansão da grande empresa, mas não podem ser compreendidas como sendo as únicas manifestações da tendência à centralização do capital. A subcontratação, principalmente no setor têxtil, também se constitui numa forma de centralização, muito embora neste caso a propriedade dos capitais envolvidos continue mantendo autonomia jurídica. A subcontratação se refere a um contrato estabelecido entre duas partes, em que uma, a parte contratada, se compromete a produzir parcela ou toda a produção, para a parte contratante. Esta relação permite à empresa que contrata, internalizar ao processo de valorização que ela controla, um ciclo de valorização externo, que não lhe pertence. Porisso, embora se mantenha a autonomia jurídica das unidades envolvidas, a empresa que contrata a produção estabelece uma relação de dominação sobre a contratante.

Durante as últimas décadas a subcontratação na indústria têxtil se revitalizou. É em Americana, tradicional centro têxtil no Interior do Estado que a subcontratação é bastante expressiva. Em geral, nas relações de subcontratação o que ocorre é mais a perda de autonomia dos ciclos de valorização pelas pequenas e médias empresas, do que propriamente uma atuação autônoma destas.

Inúmeras indústrias trabalham exclusivamente para complementar a produção de um outro industrial. Em geral a produção tende a abastecer um mercado consumidor de baixo padrão aquisitivo. Assim, a subcontratação se revitaliza no seio de uma perversa concentração de renda.

Um exemplo muito expressivo da prática da subcontratação é o da indústria TPS, grupo Cianê, - um dos grandes grupos econômicos do país. A TPS se constitui numa indústria têxtil sem teares. Sem teares, como divulga em campanhas de marketing, porque é especializada na con- cepção de tecidos, repassando a produção, a terceiros. Realiza-se, assim, dada a possibilidade da desintegração da produção, a existência de uma indústria têxtil sem teares. ${ }^{16}$

Queremos ressaltar que tanto as formas de centralização através das associações, absorções e fusões, como através do desenvolvimento da rede de subcontratação são práticas empresariais do setor têxtil bastante presentes na atual reestruturação da indústria. Tais práticas centralizadoras redimensionaram a localização industrial de muitos estabelecimentos, aspecto que vamos discutir a seguir.

\section{NASTRAMASDA REESTRUTURAÇÃO ESPACIALDA INDÚSTRIA TÊXTIL}

A relocalização dos estabelecimentos têxteis se constitui num dos elementos que estruturam e conformam um novo espaço metropolitano. Procuraremos apresentar como a reestruturação da indústria têxtil através do crescimento das grandes empresas e da ampliação da rede de subcontratação, consolidam, na aglomeração e dispersão das unidades de produção, uma nova materialidade espacial.

A nosso ver, o exame conjunto destas referências empresa e distribuição espacial de estabelecimentos têxteis - contribui para o conhecimento da reestruturação urbanoindustrial do Estado de São Paulo, à medida que esta reestruturação envolve tanto processos sociais como processos espaciais. Primeiramente procedemos ao mapeamento do número e distribuição dos estabelecimentos têxteis nos anos 1970,1980 e 1988, que nos permitiu uma primeira aproximação com a dinâmica da distribuição espacial dos estabelecimentos têxteis no Estado de São Paulo: sua concentração e dispersão.

(15) A Cianê tem sua origem na Fabrica de Alvejaria, Tinturaria e Estamparia de São Paulo, do começo do século, de propriedade da Kenworthy \& Cia. Em 1940, se expandiu; Severino Pereira da Silva incorporou o controle da Fabrica de Tecidos Santo Antônio e da Fabrica de Tecidos Santa Rosália, todas situadas em Sorocaba. Mais tarde adquiriu a Fábrica Paraguaçu Têxtil de Minas Gerais e, em 1981, a Matarazzo. Textiles Panamericanos: octubre/ $1984 ; 48$.

(16) Folha de São Paulo, 31/10/1990. 
ESTADO DE SÃO PAULO NÚMERO DE ESTABELECIMENTOS TÊXTEIS 1970-1988

1970

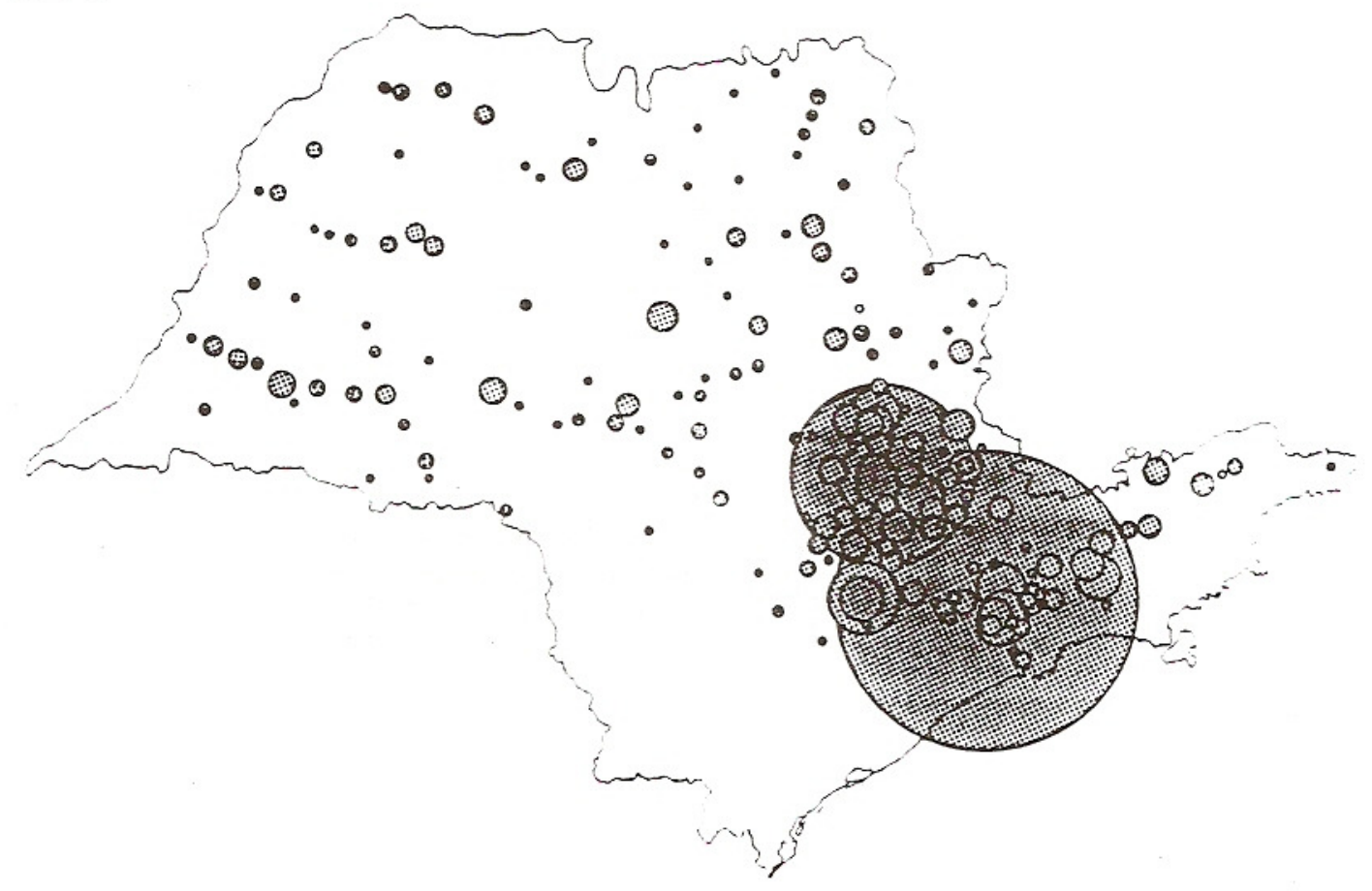

1980

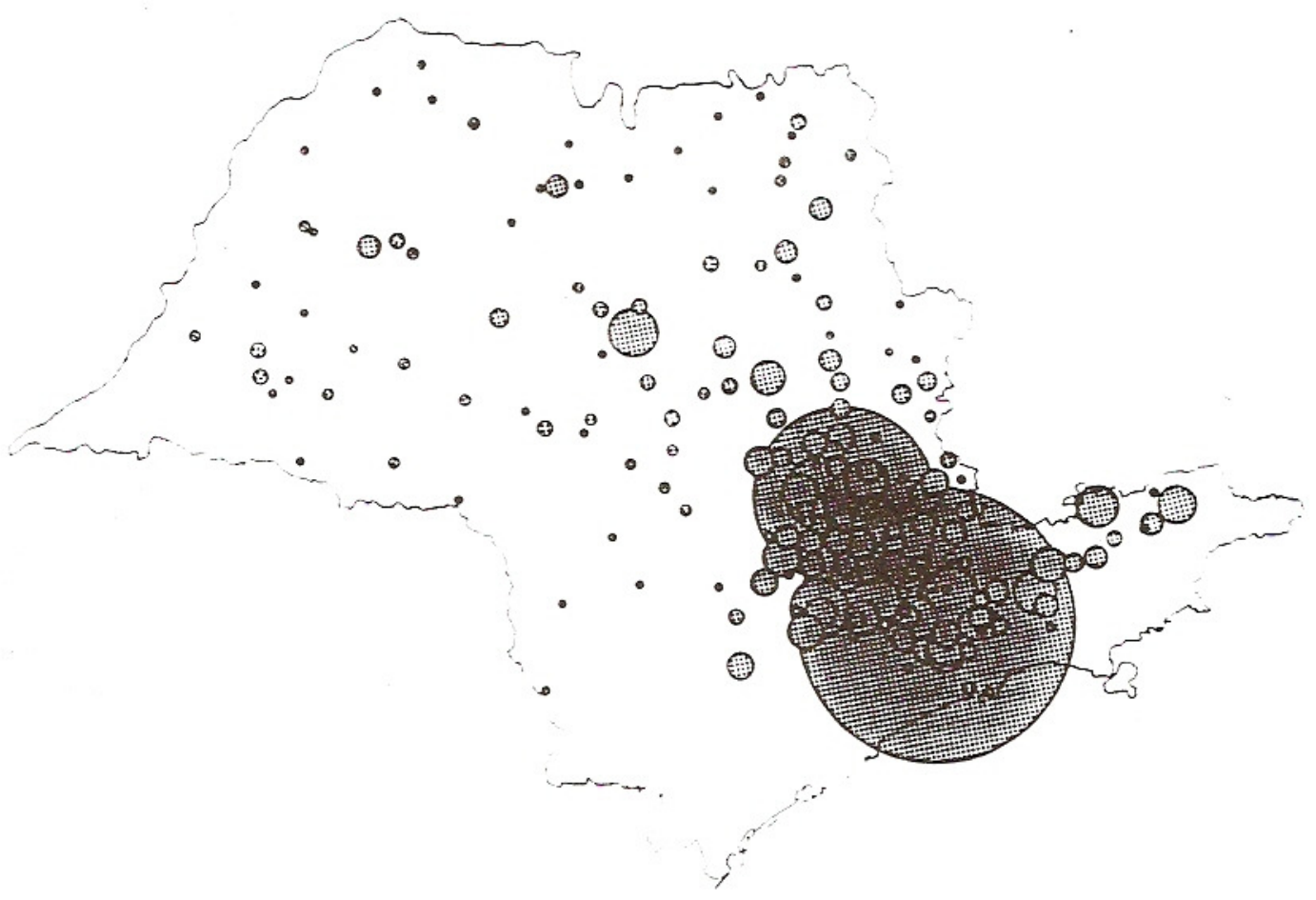




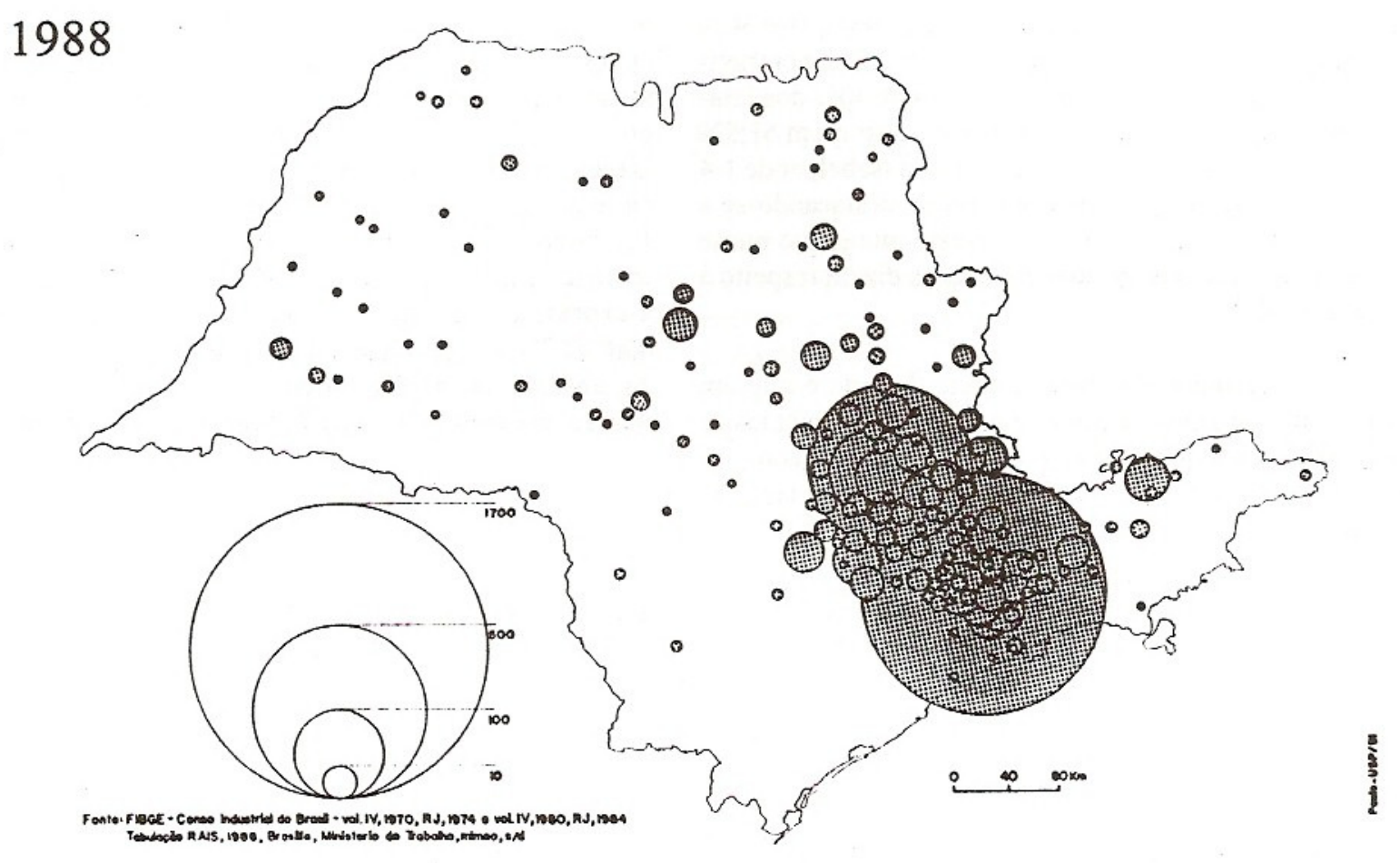

Os mapas foram reveladores da dinâmica da localização dos estabelecimentos têxteis. O número de estabelecimentos diminuiu no município da Capital, ao mesmo tempo que cresceu em importância nos arredores da Região Metropolitana, em direção ao Interior. As demais áreas do Interior, principalmente as do Oeste do Estado, conheceram um processo de desindustrialização têxtil. Este esvaziamento do Interior mais distante evidencia a força centrípeta da metrópole em expansão que conforma um espaço mais amplo, mas ao mesmo tempo, denso na sua proximidade.

Utilizando pesquisa do SENAI(1989) e FIESP/CIESP (1991) analisamos alguns municípios do Interior localizados num raio de $150 \mathrm{~km}$. a partir da Capital ou localizados junto aos principais eixos rodoviários e pudemos constatar que destacam-se por instalações recentes de estabelecimentos têxteis, ou seja referentes ao período 1974 a 1988, os municípios de Ribeirão Bonito, São Carlos e Jacareí, cada um deles, praticamente com cerca de $1 / 3$ dos seus estabelecimentos têxteis instalados neste período. ${ }^{17}$ Em relação aos municípios da Região Metropolitana, excetuando-se a Capital, dentre os muitos exemplos a serem citados, destacamos os municípios de Osasco com 73,3\% dos estabelecimentos instalados neste período, Guarulhos, com 57,4\%, Poá, com $80 \%$ e São Bernardo do Campo, com 55\%. ${ }^{18}$

Dentre os municípios da Região Metropolitana, em que a maior parte dos estabelecimentos têxteis foi instalada na década de 80 , excetuando-se a Capital, destaca-se os municípios de Cotia, Itapevi, Jandira e Santa Isabel, em que $50 \%$ dos estabelecimentos foram instalados neste período. No Interior sobressai Atibaia, com a cifra de $66 \%$ dos estabelecimentos têxteis instalados nesta década e o município de Lençóis Paulista com 66,6\%. ${ }^{19}$

Segundo pesquisa do SENAI (1987), as grandes indústrias têxteis se localizam, sobretudo, no Interior. ${ }^{20} \mathrm{Em}$ geral é na indústria têxtil que se concentra grande parte dos empregos urbanos deste municípios. Este é o caso, por exemplo, de Ribeirão Bonito onde $33,3 \%$ dos estabelecimentos são de grande porte e responsáveis por $82,1 \%$ dos empregos têxteis da cidade e $88,3 \%$ dos empregos urbanos. É também o caso de Jaú, onde somente a Cia Jauense Industri-

(17) Precisamente, Ribeirão Bonito com a cifra de $33,3 \%$, São Carlos, com $30 \%$ e Jacareí com $27,3 \%$. Fonte: SENAI-SP/ DPEA: 1988 b ; 244, 251, 147.

(18) Fonte: SENAI-SP/DPEA: 1988a; 193; 117; 211, 271 e FIESP/CIESP (1991), mimeo.

(19) Fonte: SENAI-SP/ DPEA: 1988a; 49,137, 155, $243 \mathrm{e}$ SENAI-SP/DPEA: 1988b; 177, 35.

(20) Cf. SENAI-SP/DPEA: 1987; 16. 
al, do grupo Camargo Correa, é responsável por quase $30 \%$ do emprego urbano. Na Região Metropolitana encontramse exemplos semelhantes: Carapicuíba, onde 50\% dos estabelecimentos têxteis são de grande porte e absorvem $61,5 \%$ do emprego têxteis do município e de Santa Isabel, onde 1/4 dos estabelecimentos são de grande porte, destacando-se a Karibê S/A Indústria e Comércio. Neste município quase $50 \%$ dos empregos nas atividades urbanas dizem respeito à indústria têxtil. ${ }^{21}$

Uma segunda observação digna de nota é que em alguns municípios em que predominam estabelecimentos de pequeno porte - os que empregam de 5 a 99 empregados -, o emprego na indústria têxtil pode ser, ou não, importante no conjunto dos empregos urbanos deste municípios depen- dendo da diversidade das atividades urbanas destes municípios. No caso de Ribeirão Bonito $66,7 \%$ de estabelecimentos têxteis são de pequeno porte absolvendo apenas $17,9 \%$ dos empregos têxteis da cidade. Também é o caso de Santa Isabel, na Região Metropolitana, onde em $75 \%$ de estabelecimentos têxteis de pequeno porte estão alocados apenas $11,9 \%$ dos empregos têxteis deste município. ${ }^{22}$ Inversamente, alguns municípios tem na indústria têxtil de pequeno porte a expressão dos empregos urbanos, como em de Araras, com $92,3 \%$ dos estabelecimentos têxteis situados nesta faixa, absorvendo $54,8 \%$ do emprego têxtil do município e Araraquara com índices de $75 \%$ e $54 \%$, respectivamente. ${ }^{23}$

\section{ESTADODE SÃO PAULO-ESTABELECIMENTOS TÊXTEISE PESSOAL OCUPADO SEGUNDO REGIÕES ADMINISTRATIVAS 1970-1988}

\begin{tabular}{|l|r|r|r|r|r|r|}
\cline { 2 - 7 } \multicolumn{1}{c|}{} & \multicolumn{2}{c|}{1970} & \multicolumn{2}{c|}{1980} & \multicolumn{2}{c|}{1988} \\
\hline Regiões & Est. & $\begin{array}{c}\text { Pessoal } \\
\text { Ocupado }\end{array}$ & Est. & $\begin{array}{c}\text { Pessoal } \\
\text { Ocupado }\end{array}$ & Est. & $\begin{array}{c}\text { Pessoal } \\
\text { Ocupado }\end{array}$ \\
\hline Metropolitana & 1786 & 114299 & 1674 & 99184 & 1448 & 105371 \\
\hline Campinas & 1033 & 30614 & 1141 & 44144 & 982 & 56204 \\
\hline Sorocaba & 148 & 16536 & 152 & 17869 & 121 & 24557 \\
\hline Vale do Paraíba & 75 & 24557 & 85 & 9920 & 61 & 6948 \\
\hline Demais Regiões & 209 & 14438 & 142 & 15389 & 154 & 16934 \\
\hline Total do ESP & 3251 & 185312 & 3194 & 186506 & 2766 & 210006 \\
\hline
\end{tabular}

Fonte: FIBGE - Censo industrial do Brasil, vol. IV,1970, Rio de Janeiro, 1974. FIBGE - Censo industrial do Brasil, vol. IV, 1980, Rio de Janeiro, 1984.

Tabulação RAIS, 1988, Brasília, Ministério do Trabalho, mimeo, s/d.

(21) Fonte: SENAI-SP/DPEA, 1988b: 155-157, 243. SENAI-SP/DPEA, 1988a: 37-38, 241-242 e FIESP/CIESP (1991), mimeo.

(22) Fonte: SENAI-SP/DPEA, 1988b 155-156, 241-242.

(23) Fonte: SENAI-SP/DPEA, 1980b; 23-24, 3-4. 
Assim, poderíamos dizer que nos municípios do Interior em que há estabelecimentos de grande porte, o emprego na atividade têxtil tende a ser significativo no conjunto do emprego urbano, mas em relação aos estabelecimentos de pequeno porte não há uma correlação direta entre a dimensão do porte dos estabelecimentos e emprego urbano.

A partir dos dados da tabela abaixo, que pode ser directamente visualizada na representação dos histogramas a seguir, pode-se perceber a proporção de estabelecimentos e pessoal ocupado na indústria têxtil, conforme as regiões administrativas do Estado de São Paulo nos anos de 1970, 1980 e 1988.

A distribuição espacial, tanto dos estabelecimentos têxteis, como do pessoal ocupado na indústria têxtil, se apresenta claramente concentrada na Região Metropolitana e na Região Administrativa de Campinas. Entretanto, enquanto a Região Metropolitana apresenta um declínio nos dois aspectos considerados, a Região Administrativa de Campinas, embora oscile quanto ao número de estabelecimentos, conhece um claro aumento do pessoal ocupado. Em relação ao Interior, o número de estabelecimentos tende à diminuir sua participação relativa nas Regiões Administrativas de Campinas, Sorocaba e Vale do Paraiba e a estabilizar no conjunto denominado Demais Regiões do Estado. Quanto ao pessoal ocupado, o maior crescimento se dá na Região Administrativa de Campinas, seguido de Sorocaba e Demais Regiões Administrativas do Estado.

Analisando-se, não mais os estabelecimentos industriais, mas a empresa e sua relação com o espaço, buscamos superar o obscurecimento dos dados levantados por unidades fabris, ou em outros termos, segundo a distribuição das plantas. Em primeiro lugar, é importante ressaltar, quantas vezes necessário for, que no caso da empresa com várias unidades de produção - ou várias plantas -, o controle dos vários ciclos de valorização do capital é indireto. Não há ampla autonomia jurídica nas diversas unidades. Toda produção pertence a uma empresa, conglomerado ou grupo, subordinada a uma mesma direção e disposição geral do capital.

Neste caso, a dispersão dos estabelecimentos tende a se dar de uma forma mais extensiva, quase distendida. Tanto que a dispersão ocorre não só em relação às unidades de produção, como também em relação às funções comerciais e administrativas. O gerenciamento da empresa, distante da produção, se constitui numa possibilidade cada vez mais presente e contemporânea. A partir desta segmentação a reaproximação das múltiplas etapas da produção e funções da empresa se recompõem como uma redefinição da relação espaço-tempo: aproxima lugares e elimina distâncias.

A partir de uma série de levantamentos pudemos identificar estabelecimentos industriais têxteis pertencentes a grupos econômicos e mesmo estabelecimentos juridicamente autônomos que embora se localizem no Interior, possuem o gerenciamento da empresa na Capital. ${ }^{24}$

Apenas com o intuito de tomar mais claro o levantamento feito, tomemos de início os estabelecimentos têxteis relacionados aos grupos e empresas estrangeiras que embora se localizem no Interior, têm o gerenciamento na Capital. Entre os grupos japoneses, cabe destacar o grupo Kanebo, com unidades de produção em São José dos Campos, Jundiaí e Mogi das Cruzes. O grupo Shoei Co, com a indústria Sedas Shoei Bratac S/A, em São José do Rio Preto e duas unidades da Fiação de Seda Bratac, uma em Bastos e outra em Duartina. O grupo Toyobo, com um estabelecimento em Americana. A empresa Nisshimbo do Brasil Indústria Têxtil Ltda, em Itapetininga, Unitika do Brasil Indústria Têxtil Ltda, em Americana. Além destes, de origem japonesa, cabe destacar, o grupo francês, Rhodia, com unidades têxteis em Jacareí, São José dos Campos, Santo André e São Bernardo do Campo, e o grupo holandês Akzo N.V., com a indústria Polyenka S/A em Americana e a empresa Du Pont do Brasil, em Paulínea. Embora o grupo inglês Paramount não tenha mais unidades de produção no Estado de São Paulo, estando seus estabelecimentos localizados particularmente em Sapucaia do Sul, Bagé, Esteio e Canela, cidades do Rio Grande do Sul, é significativo o fato do escritório geral desta empresa se localizar na cidade de São Paulo.

Considerando-se os principais grupos nacionais têxteis, verificamos que podemos afirmar que as maiores empresas localizadas no Interior tendem a localizar o geren-

(24) Dada as fontes utilizadas, o levantamento diz respeito aos estabelecimentos de mais de 100 empregados. Utilizamos o levantamento feito pela FISP/CIESP (1991) que arrola os estabelecimentos industriais com mais de 100 empregados no Estado de São Paulo, o levantamento de "Quem é Quem na Economia Brasileira" da revista Visão: setembro/1987, ano XXXVI, no 39, o Anuário das Indústrias de 1987/88 e 1989/90, da Editora Pesquisa e Indústria Ltda, São Paulo e a Lista Telefônica Telesp-1990/91 do Município de São Paulo. 
ciamento na Capital. O grupo Vicunha, por exemplo, possui vários estabelecimentos no Interior, mas o gerenciamento do grupo localiza-se em São Paulo. Dentre suas empresas, examinemos alguns casos. A empresa Elizabeth S/A Indústrias Têxteis tem várias unidades. Além de duas na Capital, tem duas em Americana, uma em São Manuel e duas em Itatiba. Em Americana, do grupo Vicunha ainda se localizam as empresas Fibra S/A - Fiação Brasileira de Rayon e a Vanini S/A Indústria Têxtil. Em Santa Bárbara do Oeste estão duas unidades da Campo Belo S/A Indústria Têxtil. Apenas com o objetivo de demonstrar a dimensão deste grupo, mencionamos que a Campo Belo S/A Indústria Têxtil possui, além das unidades de Santa Bárbara do Oeste, duas unidades na Capital e que a Vicunha, empresa que empresta nome ao grupo, tem duas unidades de produção na cidade de São Paulo.

Outros grupos reforçam a pertinência de nosso argumento por localizarem o gerenciamento na Capital, embora as fábricas se localizem no Interior. A Cia Nacional de Estamparia (Cianê), do grupo Severino Pereira da Silva, tem duas unidades em Rio Claro, uma em Ribeirão Preto, outra em Leme e, ainda, três em Sorocaba. A Companhia Jauense Industrial, do grupo Camargo Corrêa, localiza-se em Jaú, a Deslor S/A Indústria e Comércio, do grupo Destaillieur, em Itapevi, a Fabrica de Tecidos Tatuapé do Grupo Sanflu (Santista), tem três unidades, uma em Americana, uma na Capital e uma em Osasco. Pertence à este grupo a empresa Brasital S/A Indústria e Comércio, localizada em Salto.

Há também o caso de indústrias que não pertencendo a nenhuma grande empresa ou mesmo grupo econômico, tem a unidade de produção no Interior ou nos municípios da Região Metropolitana, mas mantém escritório em São Paulo. Neste caso a permanência da gerência da empresa na cidade de São Paulo indica o controle direto e centralizado do processo de valorização do capital a partir da Capital. ${ }^{25}$

Analisando-se outra face da centralização, a subcontratação e sua relação com o espaço, gostaríamos de primeiramente observar que não há nenhum anacronismo na subcontratação e sua importância para a configuração espacial da indústria tem sido objeto de análise de muitos autores. Para Allan J. Scott, que se refere à subcontratação como desintegração da produção, "where there is a proliferated desintegration of production process such that many small and specialized producers are intertwined within a network of constantly changing linkages, then we may expect there to be correspondingly strong pressures on plants to convergence together in geographical space. By means of such converge potentially onerous linkages costs may be held down to a minimum." (SCOTT; 1983; 242)

Um outro autor, John Holmes embora afirme que poucas conclusões possam ser apresentadas a respeito da configuração espacial da subcontratação, considera que quando as relações de subcontratação envolvem estabelecimentos de pequeno porte e quando tais relações não são suficientemente permanentes, tende a haver um agrupamento espacial dos estabelecimentos. Inversamente, a rede de subcontratação tende a ser geograficamente mais dispersa quando os vínculos entre as partes são mais permanentes, envolvem produção de maior escala e quase sempre dizem respeito a empresas maiores. ${ }^{26}$

No caso de empresas menores a proximidade locacional em relação à empresa contratante chega ser decisiva e se constitui num aspecto relevante da distribuição espacial da indústria têxtil no Estado de São Paulo. Para a empresa que contrata, manter-se a pequena distância das empresas subcontratadas se constitui, de certo modo, garantia do exercício de controle do produto encomendado e, sobretudo, da entrega nos prazos combinados. Portanto, quanto maior for a dependência de negociações e entendimentos no exercício das encomendas às empresas subcontratadas, maior se torna a necessidade de aglomeração espacial das empresas envolvidas nesta relação. Assim, a centralização do controle de valorização do capital, via desenvolvimento da rede de subcontratação se constitui num elemento fundamental para a compreensão da distribuição dos estabelecimentos industriais. Porém, como alerta Dorren Massey (1985), a subcontratação representa potencialmente diferentes relações envolvendo indústria e espaço, portanto, o essencial é não se apegar a nenhuma tipologia. ${ }^{27}$

(25) O número de empresas do Interior ou da Região Metropolitana com gerenciamento na Capital é de 30. Este dado é apenas indicativo da tendência desta cisão: produção e gerenciamento da empresa segmentados espacialmente. Fonte: FIESP/CIESP , Cadastro Industrial, mimeo, 1991. Quem é Quem na Economia Brasileira, revista Visão: setembro/1987, ano XXXVI, n.39. Anuário das Indústrias de 1987/88, São Paulo, 1988 e 1989/ 90, São Paulo, 1990, Editora pesquisa e Indústria Ltda.

(26) Cf. HOLMES: 1986; 80-106.

(27) A questão da relação entre estruturas espaciais e produção capitalista é discutida por MASSEY (1985), no capítulo 3, "Uneven Development and Spatial Structures." 
No caso da subcontratação, a eficácia desta forma de centralização exige entendimentos constantes entre contratante e contratado. A necessidade das negociações quanto mais frequentes e contínuas, tanto quanto o fluxo de matérias-primas, assistência técnica... tende a produzir uma rede de subcontratação. Em outros termos, o fato de que nas relações de subcontratação o controle ser indireto, dada a manutenção da autonomia jurídica dos capitais envolvidos, acaba por se tornar importante a existência de uma proximidade entre as unidades a fim de se poder exercer o controle econômico. Porisso é que a rede de subcontratação, sobretudo quando envolve indústrias de pequeno porte, tende a ser concentrada espacialmente. Este é o caso da rede de subcontratação presente na região de Americana, como dissemos, tradicional reduto têxtil do Estado de São Paulo.

No caso dos estabelecimentos têxteis de menor magnitude de capital, a proximidade locacional entre a empresa contratante e as contratadas procura garantir o exercício de controle do produto encomendado e, sobretudo, da entrega nos prazos combinados. Portanto, quanto maior for a dependência de negociações e assistência, a necessidade de aglomeração espacial das empresas envolvidas nesta relação. Assim, a centralização do controle de valorização do capital, via desenvolvimento da rede de subcontratação se constitui num elemento fundamental para a compreensão da distribuição dos estabelecimentos industriais.

Quanto à grande empresa que utiliza a estrutura de subempresas multilocacionais e/ou da rede de subcontratação, esta pode estar integrada vertical ou horizontalmente. Até mesmo ambas formas de integração da produção têxtil podem ocorrer. No primeiro caso, diferentes fases do processo de produção, desde a elaboração da matériaprima até o produto final, por exemplo, são integradas num mesmo ciclo de valorização. Exemplificando, desde a produção do algodão, fiação, tecelagem, tingimento, até o acabamento. Neste caso tende a ocorrer uma divisão espacial do processo de produção.

No segundo caso, de integração horizontal, são reunidas várias unidades que produzem o mesmo produto. $\mathrm{O}$ que está posto não é a integração de fases do processo de produção, portanto a da divisão técnica do trabalho. O que está posto é que se trata de uma integração de unidades clones, ou seja, integração de unidades que se repetem igualmente, salvo em relação à capacidade da produção. Portanto, a integração horizontal diz respeito a uma estrutura in- dustrial em clone. $O$ fato das unidades de produção estarem separadas da gestão, em nada modifica a questão.

Discutindo a tendência da empresa moderna integrar-se tanto vertical como horizontalmente, Harry Braverman deixa claro que o significativo é o fato de que se integram "produtos e serviços que não exibem relação visível uns com os outros, exceto em sua função como fontes de lucro." (BRAVERMAN; 1981; 225 e 226).

Gostaríamos de assinalar, ainda, como a integração, quer vertical ou horizontal, se constitui, a rigor, numa desintegração da produção que conforma a estrutura espacial. No âmbito de nossas preocupações é importante assinalar que quanto mais desenvolvida for esta desintegraçãointegração, mais a estrutura espacial desenhará labirintos no espaço. De modo que o processo de centralização do capital através desta desintegração-integração, não configura apenas uma forma.

De acordo com o desenvolvimento da empresa moderna, há uma tendência de se cindir no espaço, de um lado, a produção imediata e, de outro, a concepção, a pesquisa e desenvolvimento de produtos, as vendas e a administração. Esta tendência encontra na grande empresa multilocacional, o seu exemplo mais desenvolvido. Todavia, esta ideia generalizada de divisão espacial, em função desta manifestação da estrutura da empresa moderna, tem que ser colocada em seus devidos termos. Primeiro, cabe reafirmar que se trata de uma tendência, não de uma regra. Segundo, que esta cisão, em seu sentido amplo, não diz respeito apenas ao âmbito da estrutura da empresa moderna, em que a produção se separou do mercadejamento e da estrutura de gerenciamento, para usar termos bravermanianos. Terceiro, que esta ideia distanciamento da produção em relação à gerência, é válida, sobretudo em relação à gerência superior das empresas, na medida que esta tende a se localizar em São Paulo. ${ }^{28}$ Quanto à pesquisa e desenvolvimento, um estudo recente encontrou laboratórios na maioria dos estabelecimentos consulta-

(28) A concepção separada da produção não está ausente na reestruturação da indústria têxtil do Estado de São Paulo, inclusive envolvendo a subcontratação. Um exemplo expressivo é o da empresa TPS, uma indústria têxtil sem teares, já anteriormente referida. Esta empresa de design têxtil é especializada na concepção de tecidos a serem fabricados por outras empresas como se fossem produtos produzidos por ela. (Cf. Folha de São Paulo, 31/ 10/1990) 
dos. ${ }^{29}$ Fora dos estabelecimentos, os laboratórios de pesquisa e importantes escolas de formação técnica e profissional se localizam tanto na Capital como no Interior, particularmente em Americana.

O crescimento da importância da indústria no Interior só se viabilizou devido a expansão das condições gerais de reprodução do capital. Um exemplo, são os indicadores de consumo de energia elétrica. Para o período entre 1980 e 1984, o consumo de energia elétrica apresenta uma taxa de crescimento maior no Interior do que na Região Metropolitana e Capital, locais onde o consumo de energia elétrica tem crescido a taxas inferiores à média estadual. ${ }^{30}$ Estendendo-se este período até 1988 e considerando apenas o consumo de energia elétrica para uso industrial, embora tenha havido um aumento absoluto deste consumo na Capital, o qual passou de 5.622.949 para 7.204.867 mwh., este significou uma participação menor em relação ao consumo médio do Estado. ${ }^{31}$

Um segundo exemplo diz respeito à expansão da rede rodoviária nos últimos vinte anos, significando não só novas pistas de rodagem, mas sobretudo, duplicação de pistas e a adoção de um padrão internacional para os corredores de tráfego que confluindo para a Região Metropolitana de São Paulo. Estas transformações tornaram mais coeso e integrado o território paulista, porque diluiu distâncias e, principalmente, distendeu o espaço metropolitano..$^{32} \mathrm{~A}$ redefinição deste espaço foi fundamental no sentido de se opor às porosidades havidas na reprodução do capital por contrarestar as possibilidades de desvalorização do capital imposto pelo tempo de circulação.

Esta coesão e integração significa homogeneização, mas isso não quer dizer que as diferenças são anuladas. As diferenças entre os lugares se redefinem fazendo com que estes assumam novas funções integradoras do ciclo de valorização do capital. Ainda que cada lugar seja alcançado de maneira diferente pelo processo de integração exigente de menor porosidade entre os elos deste ciclo, as diferenças persistem. A medida que a integração entre as cidades se intensifica e se desenvolve as telecomunicações e as redes de informática podemos dizer que circula-se mais informações e decisões do que produtos.

\section{À GUISADE CONCLUSÕES}

A indústria têxtil no Interior vem tendo importância crescente se comparada à da Capital. Analisando-se os da- dos desde 1950 pudemos observar que na Capital e nos municípios da Região Metropolitana o número absoluto de estabelecimentos têxteis, de operários e o valor da transformação industrial têm decrescido desde $1950 .{ }^{33}$ Todavia, no Interior o número de estabelecimentos têxteis tem aumentado e, em relação ao número de operários, embora tenha igualmente descrescido, este número se fez a taxas expressivamente inferiores à da Capital. Tanto que, se na década de 70 o decréscimo do número de empregos têxteis na Capital foi de $18,4 \%$, no Interior e demais municípios da Região Metropolitana, este decréscimo foi apenas de $1,6 \%{ }^{34}$

Mas, se a interpretação do processo descrito for compreendido como descentralização industrial há um duplo equívoco. Em primeiro lugar, como vimos, todo o oeste do Estado, que perdeu estabelecimentos têxteis não é considerado nesta interpretação. Em segundo lugar, fica obscurecido o processo de centralização do capital - as grandes empresas com sua rede de unidades multilocacionais e a subcontratação - que caracteriza as transformações da indústria têxtil nas últimas décadas. Acaba-se por se inverter a compreensão do processo de reestruturação industrial que, em vez de se explicitar como processo de centralização do capital, fica explicado como produto de um processo de descentralização industrial.

(29) "A crescente complexidade da produção têxtil (constante crescimento, diversificação e melhoria da qualidade dos produtos) tornou necessária a criação, dentro das empresas, de outros setores voltados para o atendimento de aspectos específicos dessa produção Tal é o caso, por exemplo, da criação de laboratórios para testes e ensaios físicos e químicos de fios e tecidos." (SENAI-SP/ DPEA: 1987; 21)

(30) A taxa de crescimento anual do consumo de energia elétrica na Capital e Região Metropolitana é respectivamente 4,449 e 4,366, enquanto a do Interior é de 7,812, maior inclusive que a taxa estadual de 6,069 a.a.. Fonte: Hierarquia das Regiões e dos Municípios no Estado de São Paulo, SINERG: 1987; 47.

(31) Em 1980 o consumo de energia elétrica para uso industrial na Capital representava 22,2\% do Estado e em 1988, 19,2\%. Fonte: SEADE: $1990 ; 35$.

(32) "Em sua estratégia para o setor de transportes, a administração paulista analisou as ligações com o crescimento econômico previsto para as próximas décadas e constatou que a cidade de São Paulo continua sendo o grande pólo irradiador. Além deste, destacam-se outros pólos constituídos pela Região Metropolitana e pelas Regiões de Campinas/Jundiaí, Sorocaba, Vale do Paraíba e Baixada Santista. Aí vivem dois terços da população paulista e são gerados 90\% da arrecadação do ICMS." (CARLETTO: 1990; 23)

(33) Censo Industrial 1950, 1960, 1970 e 1980. FIBGE, Rio de Janeiro.

(34) SEADE: $1988 ; 28$. 
A nosso ver a recente reestruturação espacial da indústria têxtil no Estado de São Paulo não ocorre devido a um processo de descentralização industrial. Ela envolve um processo de ampliação e consolidação do espaço metropolitano através da instalação de fábricas fora da Capital, mas nas imediações da Região Metropolitana e bastante vinculada ao centro da metrópole - a cidade de São Paulo -, local de gestão de muitos estabelecimentos industriais.

$\mathrm{Na}$ Capital a administração comercial, os contatos com outras empresas e com órgãos financeiros e políticos encontram condições de fluir mais facilmente devido a concentração das instituições governamentais, financeiras, empresariais e de pesquisa e, ainda, devido à concentração da rede de comunicações e serviços. Assim, o centro da metrópole se reafirma; a primazia da Capital se consolida ainda mais graças ao adensamento cada vez maior dos mecanismos de controle e decisão da produção industrial

Repetindo, em torno da Capital a tendência a homogeneizarem-se as condições gerais de produção ampliou e consolidou o espaço metropolitano de maneira a desconcentrar a metrópole de São Paulo e sua região. Neste espaço as formas e conteúdos urbanos, que até então eram específicos da Capital, se multiplicaram. Não só foram as condições necessárias à reprodução social do capital industrial que se ampliaram no espaço, mas, também, as condições que este capital procurou superar: encarecimento do preço da terra, alto custo do congestionamento urbano, piora da qualidade de vida e do meio ambiente etc.. As contradições e penúrias urbanas típicas das grandes metrópoles dos países de industrialização recente, aí são reproduzidas: degradação do meio ambiente, poluição ambiental, problemas de transportes, saúde, educação, saneamento, delin-quência, moradia, crescimento de favelas e, sobretudo, desemprego.

Embora tenhamos analisado especificamente um ramo da produção industrial e uma metrópole específica - São Paulo - pudemos constatar que dentre os processos contidos na atual reestruturação urbano-industrial está presente os processos de concentração e centralização do capital, quer pelo crescimento das grandes empresas, quer pelo desenvolvimento da rede de subcontratação. Esta observação é importante porque desvincula da análise da reestruturação atual a perspectiva determinista tecnológica, que procura vincular transformação urbano-industrial com transformações no processo produtivo. Este caso ilustra que pode haver reestruturação sócio-espacial sem ocorrência significativa de processos produtivos denominados flexíveis.

Na reestruturação da indústria têxtil está contido elementos que compõem um espaço metropolitano mais expandido, onde a integração entre as cidades se intensifica a cada dia atualizando a antiga estrutura urbana do Estado de São Paulo e reiterando o primado da Capital.

\section{RESUMÉ}

Dès les années 70 , on observe une expansion industrielle tendant à gagner les régions plus reculées de l'Etat de São Paulo. A partir de cette nouvelle paysage, on a souvent interprété les transformations de l'espace et de l'industrie comme étant liées au processus de décentralisation industrielle. Une analyse minutieuse de la industrie textil permet voir que a expansion de la industrie vers la province ne peut être assimilée a un processus de décentralisation. Les établissesments manufacturiers ne cessent de se déplacer vers un espace contigu à la région métropolitaine. Mais cette dispersion ne signifie pas nécessairement décentralisation industrielle, ce processus comportant en effet une dimension sociale, c'est -à-dire relative à la dynamique de la reproduction du capital. Peu importe qu'il y ait eu dispersion d'établissements textils vers la province: de nombreuses industries en tissant des liaisons spatiales, du fait qu'elles appartiennent à une entreprise déterminée ou qu'elles sont liées à un réseau de sous-traitance, n'ont pas un caractère d'industries autonomes, c'est-à-dire capables de disposer et de contrôler les cycles de valorisation de leur capital. Dans cet tissu de relations contrôlé par une entreprise déterminée, l'autonomie de beaucoup de capitaux individuels se perd. La direction ni le contrôle du processus de valorisation du capital ne se décentralise, c'est à la rigueur de centralisation qu'il s'agit. Au sens social du processus, toute idée de décentralisation se révèle erronée. Ce n'est pas par hasard que.la gestion de la production industrielle de beaucoup d'établissements situés en province se trouvent dans la capitale, c'est-à-dire dans la ville de São Paulo.

Dans la capitale, l'administration commerciale, les contacts avec d'autres entreprises et avec des organes financiers et politiques peuvent être plus fluides grâce à la concentration des institutions gouvernementales, financières, de management et de recherche, ainsi qu'à celle du réseau de communication et de services. Ainsi, le 
centre de la métropole reprend ses droits, la primauté de la capitale se renforce encore davantage grâce à la densification sans cesse accrue des mécanismes de contrôle et de décision de la production industrielle.. C'est pourquoi nous récusons l'emploi du terme "décentralisation" pour décrire le processus que nous venons d'analyser et qui, dans le cas du secteur textile, loin d'être un processus de décentralisation industrielle, est plus exactement un processus de centralisation.

\section{BIBLIOGRAFIA}

BRAVERMAN, Harry - Trabalho e Capital Monopolista: A Degradação do Trabalho no Século XX. Rio de Janeiro, Zahar, 1981.

CARLETTO, Salvador César - "Transporte," in São Paulo em Temas. São Paulo, IGC, 1990.

FIBGE - Fundação Instituto Brasileiro de Geografia e Estatística Censo Industrial do Brasil -1950;1960;1970;1980.Rio de Janeiro, FIBGE.

FIESP/CIESP - Federação das Indústrias do Estado de São Paulo \& Centro das Indústrias do Estado de São Paulo - Cadastro industrial. São Paulo, FIESP/CIESP, mimeo, 1991

FIESP/CIESP - Federação das Indústrias do Estado de São Paulo \& Centro das Indústrias do Estado de São Paulo - Desenvolvimento Industrial Paulista. São Paulo, FIESP/CIESP, 1972.

HOLMES, John - "The Organization and Locational Structure of Production subcontracting." in Scott, A. \& Storper, M. Production, Work, Territory: the Geographical Anatomy of Industrial Capitalism. London, Allen \& Unwin, 1986, pp. 80 106.

MASSEY, Doreen - Spatial Divisions of Labour. Social Structures and the Geography of Production. London, Macmillan, 1985.

MIC/CDI/SIND - Ministério da Indústria e Comércio. Conselho de Desenvolvimento Industrial. Sistema Integrado de informações Industriais - Análise dos Setores Industriais. Estrutura. Desempenho. Problemas. Brasília, Conselho Nacional da Indústria Têxtil, 1982.

MINISTÉRIO DO TRABALHO - Tabulação RAIS, 1988. Brasília, Ministério do Trabalho, mimeo, s/d.

PRICE WATERHOUSE - Levantamento, mimeo, 1991.

SCOTT, Allen J. - "Industrial Organization and the Logic of Intrametropolitan Location: I. Theorical Considerations" in Economic Geography, vol. 59, no.3, jul., 1983, p. 233-250.

SEADE - Fundação Sistema Estadual de Análise de Dados. São Paulo (Estado) - 1990 Municipio de São Paulo. São Paulo, SEADE, 1990.

SEADE - Fundação Sistema Estadual de Análise de Dados - $C a$ racterísticas Gerais do Processo de Industrialização Paulista, São Paulo, SEADE, 1988.
SENAI-SP/DPEA - Serviço Nacional de Aprendizagem Industrial. Departamento Regional de São Paulo. Divisão de Pesquisas, Estudos e Avaliação - Região Metropolitana de São Paulo Sistematização de Dados Coletados em 1988. São Paulo, SENAI, 1988a.

SENAI-SP/DPEA - Serviço Nacional de Aprendizagem Industrial. Departamento Regional de São Paulo. Divisão de Pesquisas, Estudos e Avaliação - Municipios do Interior do Estado Sistematização de Dados Coletados em 1988. São Paulo, SENAI, 1988 b.

SENAI-SP/DPEA - Serviço Nacional de Aprendizagem Industrial. Departamento Regional de São Paulo. Divisão de Pesquisas, Estudos e Avaliação - Inovação Tecnológica e Formação Profissional na Indústria Têxtil. São Paulo, SENAI, 1987.

SINERG - Sistema de informações das regiões de Governo Presidência da República - Hierarquia das regiões e dos Municipios no Estado de São Paulo. São Paulo, SEPLAN-SAREN SINERG, 1987.

\section{OUTRAS PUBLICAÇÕES}

Jornais

Diário Comércio e Indústria

Folha de São Paulo

Gazeta Mercantil

O Estado de São Paulo

Demais Periódicos

Anuário das Indústrias

Balanço Anual/1990

Exame

Gazeta Mercantil

Lista Telefônica de São Paulo

Quem é Quem na Economia Brasileira

Textiles Panamercanos 